\title{
USO DE SENSORIAMENTO REMOTO ORBITAL PARA AVALIAÇÃO DA DISTRIBUIÇÃo ESPACIAL de CloROfila_A NA LAGOA dA ConCEIÇÃo - FlorianóPOLIS, SC
}

\author{
USE OF ORBITAL REMOTE SENSING IN THE ASSESSMENT OF SPATIAL \\ DISTRIBUTION OF CHLOROPHYLL_A IN LAGOA DA \\ CONCEIÇÃO - FLORIANÓPOLIS, SC
}

\author{
LUIZ C. P. MARTINI
}

Professor Adjunto do Departamento de Engenharia Rural

\begin{abstract}
DAVI S. MATTOS
Estudante do Curso de Agronomia - Centro de Ciências Agrárias - Universidade Federal de Santa Catarina
\end{abstract}

DÉBORA F.P. BARBOSA

Estudantes do Curso de Agronomia - Centro de Ciências Agrárias - Universidade Federal de Santa Catarina

\author{
ANDERSON I.B. RECH
}

Estudante do Curso de Engenharia de Aqüicultura - Centro de Ciências Agrárias - Universidade Federal de Santa Catarina

Recebido: 02/12/05 Aceito: 30/07/06

\section{RESUMO}

O trabalho buscou identificar a possibilidade do uso de sensoriamento remoto orbital no monitoramento da qualidade da água na Lagoa da Conceição, Florianópolis (SC), em especial do parâmetro Clorofila_a e suas implicaçóes à cor da água, propriedade que pode ser avaliada a partir de imagens de satélite. No estudo, procurou-se obter uma correlação entre os níveis de Clorofila_a medidos em amostras de água da lagoa e o padrão de resposta espectral detectado por sensores embarcados no satélite comercial Landsat TM5. Os resultados do estudo revelaram que sistemas orbitais como o Landsat TM5 podem ser utilizados na investigação de parâmetros de qualidade da água que alteram a cor superficial de corpos hídricos e a partir de imagens de satélite é possível obter distribuição espacial da concentração substâncias tais como a Clorofila_a.

PALAVRAS-CHAVE: Sensoriamento remoto, qualidade da água, clorofila.

\section{INTRODUÇÃO}

Imagens orbitais adquiridas por diversos tipos de satélite podem ser ferramentas úteis para avaliação da distribuição espacial e do status de componentes ambientais. Por sua vez, os corpos hídricos são componentes que apresentam potencial para aplicações práticas de sensoriamento remoto orbital, tanto pelas suas facilidades em interagir com a energia eletromagnética como pela sua importância estratégica.

\begin{abstract}
This work searches to identify the possibility to use orbital remote sensing in the monitoring of water quality in Lagoa da Conceição, Florianópolis, SC, specifically regarding levels of Chlorophyll_a and its implications in water color, a property which can be evaluated through satelite imagery. The aim of his study was to obtain a correlation between the levels of Chlorophylla_a found in water samples from Lagoa da Conceição and the spectral response pattern detected by sensors built into the commercial satellite TM5. The results show that orbital systems like Landsat TM5 can be utilized in the investigation of water quality parameters that effect surface color in bodies of water. Through satellite imagery it is possible to obtain the spatial distribution of concentrated substances such as Chlorophyll_a.
\end{abstract}

KEYWORDS: Remote sensing, water quality, chlorophyll. 
ral, impactos mais relevantes, um eventual processo de eutrofização acelerada poderá tornar suas águas inadequadas às atividades de lazer e turismo, com sérios reflexos à economia local.

Justifica-se, então, a execução continuada de programas de monitoramento ambiental ao longo desse corpo hídrico. Neste trabalho, investiga-se a possibilidade de avaliar o estado trófico das águas da lagoa por meio de sensoriamento remoto orbital. Para tanto, selecionou-se o parâmetro clorofila como indicador a ser medido e comparado com registros detectados por sensores orbitais na data das amostragens.

\section{CARACTERIZAC̄ÃO DA LAGOA DA CONCEIÇÂO}

Situada na ilha de Santa Catarina e pouco distante do centro de Florianópolis, SC (Figura 1), a Lagoa da Conceição é intensamente utilizada para atividades de turismo e lazer, além de atrair um número cada vez maior de pessoas interessadas em fixar residência em suas margens e adjacências. Dessa forma, existem fortes tensões ambientais em seu entorno, já que a intensa urbanização e a criação de infraestrutura turística tendem a ocasionar desequilíbrios na qualidade da água da lagoa, principalmente devido ao lançamento de dejetos urbanos sem ou com tratamento inadequado, ao escoamento de águas pluviais captadas nas áreas urbanas e ao aporte de sedimentos oriundos da ocupação das encostas e de obras de construção civil.

Tecnicamente, a Lagoa da Conceição não é um corpo hídrico isolado como seu nome indica, mas sim uma laguna, já que existe ligação de fluxo e refluxo com o mar. No entanto, como aponta Esteves (1988), no Brasil utiliza-se indistintamente o termo lagoa para referir-se a todos os corpos d'água costeiros e mesmo interiores, independente de sua origem, razão pela qual manter-se-á a denominação lagoa para o corpo hídrico estudado ao longo do texto. Ainda segundo Esteves (1988), tanto as lagunas como as lagoas da costa brasileira tiveram sua gênese durante os processos transregressivos do mar que ocorreram desde o Pleistoceno (a partir de aproximadamente 200 mil anos antes do presente) e se prolongaram até os últimos dois mil anos do Holoceno.

A Lagoa da Conceição (Figura 1) possui um eixo norte-sul com comprimento de aproximadamente $13,5 \mathrm{~km}$, largura que varia entre 0,15-2,5 km e superfície total ao redor de $20 \mathrm{~km} 2$. A lagoa está ligada ao mar por um canal estreito e raso que, de acordo com Odebrecht e Gomes Jr. (1999), apresenta 20 metros de largura e 2 metros de profundidade na entrada da lagoa. O fluxo desse canal foi regularizado com a construção de molhes na localidade Barra da Lagoa, em 1982. A amplitude das marés é inferior a 30 centímetros na lagoa, para uma amplitude de 50 centímetros na área costeira adjacente. Tradicionalmente, a Lagoa da Conceição é subdividida em lagoa de cima (porção norte), do meio (centro) e de baixo (sul). Essas subdivisões, longe de serem arbitrárias, constituem diferentes sub-sistemas do corpo lagunar. Como foi apresentado por Muehe e Gomes Jr. (1999), a lagoa de cima recebe o maior aporte de água doce da bacia (proveniente do ribeirão João Gualberto) e apresenta diferenças acentuadas nas profundidades entre a margem leste - notadamente mais rasa (profundidades inferiores a 0,5 metro) devido aos processos de deposição ao longo do cordão e esporão arenosos - e margem oeste, mais profunda (em torno de 5 metros) junto às encostas altas e íngremes. A lagoa do meio, por outro lado, possui margens rochosas tanto do lado leste como oeste, o que determina fundo monótono entre as margens em profundidades ao redor de 5,0 metros. Na lagoa de baixo, por sua vez, a profundidade é afetada prin- cipalmente pela presença de esporões na margem noroeste, que formam bancos de areia na profundidade de 0,5 metro ou menos. $\mathrm{Na}$ ausência desses bancos, a profundidade pode chegar a mais de 5 metros.

A circulação na Lagoa da Conceição tem um regime condicionado pelas marés, vento e ciclo de evaporaçãoprecipitação em sua bacia hidrográfica. Em trabalho de monitoramento nesse corpo hídrico durante 12 meses (agosto de 1983 a julho de 1984), Odebrecht e Gomes Jr. (1999) identificaram um padrão de alteração da salinidade com forte dependência do ciclo evaporação-precipitação. Assim, em períodos em que coincidiram altas taxas de evaporação e pouca chuva, as salinidades em toda a lagoa foram as mais altas de todo o período de observação. Variaçôes menos acentuadas foram associadas ao regime de ventos, principalmente sob condição de ventos do quadrante sul, os quais favorecem o ingresso de águas salgadas pelo canal da Barra da Lagoa. Em termos espaciais, os autores observaram comportamentos diferenciados na salinidade e em outras variáveis (a serem discutidas mais adiante) nas três porções da Lagoa da Conceição. $\mathrm{Na}$ lagoa de baixo (sul), a salinidade é a mais reduzida de todo corpo hídrico, com média do período de observação de 6,7 partes por mil (6,7o/oo). Tal característica está associada ao menor intercâmbio com as águas da porção central da lagoa, que apresenta maior salinidade devido à proximidade do

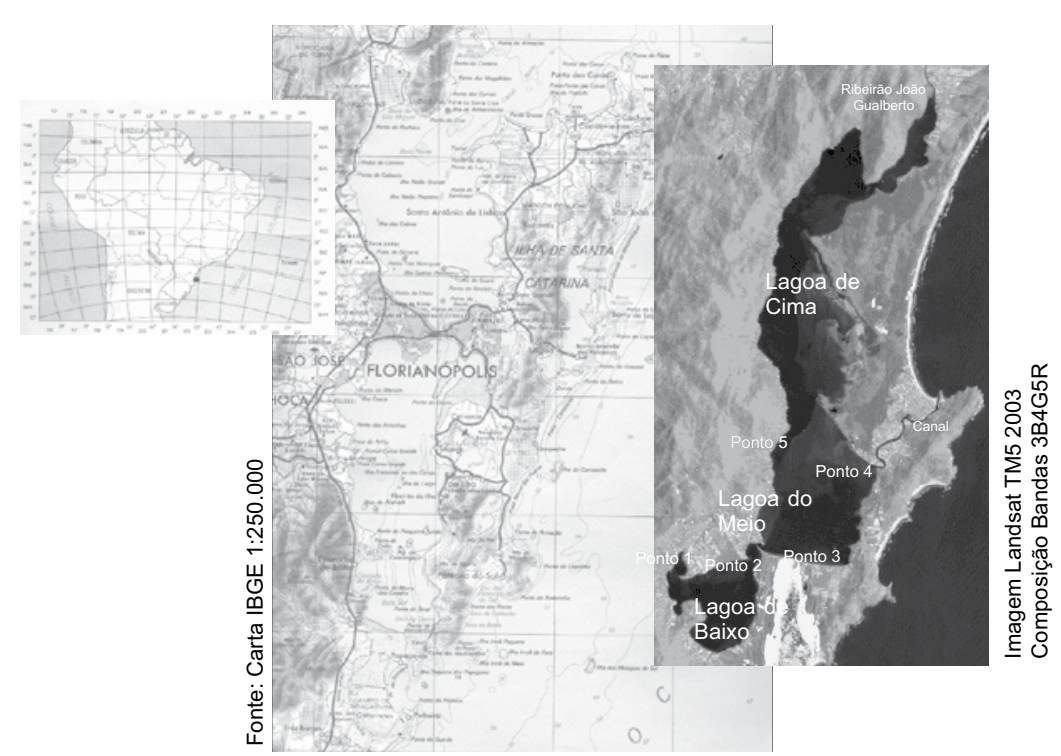

Figura I- Localização, subdivisão, pontos de amostragem e outros dados da Lagoa da Conceição, Florianópolis (SC) 
canal da Barra da Lagoa. Nessa porção, Odebrecht e Gomes Jr. (1999) identificaram estratificação halina na coluna de água: uma camada superior mesohalina ( 5 a $18 \%$ ) sobreposta a uma camada polihalina (salinidade superior a $18 \%$ ) e gradientes verticais nunca inferiores a $14 \%$. Por sua vez, na lagoa de cima (norte) a salinidade é intermediária, com média de $8,3 \%$ no período de monitoramento. A destacar que em um ponto de medida próximo à desembocadura do ribeirão João Gualberto foram obtidas salinidades de apenas $3 \%$, as menores registradas em toda a lagoa ao longo do período de monitoramento.

\section{MONITORAMENTO ORBITAL DE CORPOS D'ÁGUA}

A produtividade primária em sistemas hídricos relaciona-se diretamente com o aporte de nutrientes oriundos de ecossistemas terrestres. Devido aos ciclos biogeoquímicos naturais, condicionados principalmente pelo clima, esse aporte de nutrientes pode apresentar variaçōes sazonais típicas, com eventuais flutuações decorrentes de eventos extremos, tais como estiagens, inundaçōes ou mesmo impactos catastróficos (incêndios, por exemplo). Corpos de água lênticos, ou com predomínio de águas paradas, são naturalmente sensíveis ao enriquecimento com nutrientes, processo que é acelerado pelas atividades antrópicas. $\mathrm{O}$ estado de tensão entre ambientes ocupados pelo homem e os sistemas hídricos conectados a eles propicia a ocorrência da eutrofização cultural (ou acelerada), que foi apropriadamente denominada por Esteves e Barbosa (1992) como "doença dos lagos".

Imagens obtidas por sensoriamento remoto orbital podem ser uma alternativa para monitoramento de sistemas hídricos sensíveis. Como ilustração, destaque-se o trabalho desenvolvido por Kester et al (1996) na identificação de metais pesados em águas costeiras, em que os autores discutem a possibilidade de monitorar essas águas a partir do acompanhamento por satélite dos seus constituintes biologicamente ativos. Em escala global, a observação dos oceanos vem sendo realizada por uma nova geração de satélites que registram a coloração da água - resultante da concentração de pigmentos - e que, dessa forma, podem subsidiar a estimativa da produção de fitoplâncton marinho. Joint e Groom (2000), em um trabalho que busca apresentar o potencial de uso do sensoriamento remoto, demonstram a utilização dessa tecnologia em uma aplicação na costa da Grã-Bretanha, com resultados promissores para grandes superfícies de água. Em face do grande número de satélites disponíveis, Johannessen et al (2000) apresentam uma revisão dos produtos orbitais gerados por esses satélites para aplicaçôes em oceanografia, com destaque para potencialidades de monitoramento das águas oceânicas e discussão das limitaçôes existentes.

Em águas interiores, usos diretos da tecnologia de sensoriamento remoto por satélite são o monitoramento das águas quanto à carga de sedimentos, proliferação de macrófitas na superfície líquida e identificação de florações de algas. Um uso potencial é o monitoramento da população de organismos fotossintéticos planctônicos e não planctônicos (algas bentônicas). Todas as possibilidades listadas estão diretamente relacionadas ao aporte de nutrientes às águas e podem servir como instrumento de monitoramento de corpos hídricos sujeitos à eutrofização acelerada.

Embora existam diversos satélites em operação que disponibilizam dados oceânicos a custo zero ou baixo custo para o usuário final, tais dados são coletados em escala muito pequena, apenas permitindo avaliações em grandes superfícies de água. Para aplicações costeiras e águas interiores, atualmente os sistemas mais utilizados são o Landsat TM5 e Landsat ETM7, pois possuem preços acessíveis, apresentam resolução média ( 15 a 30 metros) e aquisição de informações radiométricas em 7 e 8 bandas espectrais, respectivamente. Esses sistemas são adequados para avaliação de comunidades vegetais terrestres e tem sido empregados no monitoramento de áreas florestadas, em queimadas e no acompanhamento de áreas cultivadas. Em adição, os produtos Landsat também podem ser utilizados nas superfícies de água, como indicam Perez Fo e Quiñones (1997) em trabalho no qual buscaram desenvolver uma metodologia para aplicação de sensoriamento remoto orbital no monitoramento da qualidade da água em represas. Os resultados desse trabalho demonstraram a existência de correlação significativa entre dados orbitais do satélite Landsat e as variáveis concentração de clorofila, teor de sólidos em suspensão e profundidade Secchi. Giardino et al (2001), de forma semelhante, utilizaram produtos Landsat na detecção de clorofila, profundidade do disco de Secchi e temperatura superficial em lagos sub-alpinos situados na Itália. Os resultados demonstraram alta correlação entre os registros orbitais e determinaçôes realizadas por amostragem direta das águas. Em um contexto diferente, Patil et al (2002) discutem a utilização de dados Landsat na avaliação de impactos ambientais causados por fazendas de camaróes estabelecidas na costa ocidental da Tailândia. Ao compararem as técnicas geo-espaciais com as convencionais, os autores concluem que as primeiras oferecem vantagens em termos de identificação das variaçōes espaciais e temporais da poluição hídrica. Com respeito à avaliação de impactos da poluição hídrica de origem industrial, Ekstrand (1998) obteve boas estimativas do teor de Clorofila_a no extrato superficial de águas costeiras a partir de dados Landsat TM, especialmente os registrados na banda 4, que detecta a reflectância na banda espectral do infra-vermelho próximo. $\mathrm{O}$ autor aponta o uso potencial desses dados no mapeamento de Clorofila_a no interior de plumas de efluentes lançados ao meio hídrico e em áreas adjacentes, variável que pode servir como indicadora do grau de poluição decorrente do lançamento de efluentes industriais.

Finalmente, deve-se destacar que alternativamente aos produtos Landsat estão disponíveis outras plataformas, caso do CBERS - Chinese-Brazilian Earth Resource Satélite ou satélite sinobrasileiro de recursos terrestres -, em que um de seus instrumentos imageadores adquire informaçōes em 5 bandas espectrais com resolução espacial de 20 metros. Devido ao fato de ser recente - a versão 1 , já desativada, foi lançada em outubro de 1999, enquanto que o CBERS2 foi lançado apenas em outubro de 2003 - os produtos CBERS ainda não estão amplamente difundidos, porém apresentam características que podem revelar-se promissoras em estudos de ecossistemas aquáticos.

\section{PIGMENTOS EM CORPOS D'AGUA}

De acordo com Raven et al. (2001), os principais pigmentos asso- 
ciados aos organismos fotossintetizantes são as clorofilas, os carotenóides e as ficobilinas. Há diversos tipos de clorofilas, que diferem entre si nos detalhes da sua estrutura molecular e nas suas propriedades específicas de absorção. A Clorofila_a é o pigmento primário de todos os organismos fotossintetizantes e está presente em todas as classes de algas. As plantas verdes, algas verdes e euglenas também contém o pigmento Clorofila_b, que possui um espectro de absorção de luz ligeiramente diferente da Clorofila_a. Para Raven et al (2001), a Clorofila_b é um pigmento acessório que serve para ampliar a faixa de luz que pode ser usada na fotossíntese. Além dessas clorofilas, existem outros tipos: a Clorofila_c substitui a Clorofila_b em alguns tipos de algas, principalmente algas pardas e diatomáceas, e as bactérias fotossintetizantes possuem ou bacterioclorofila (bactérias púrpuras) ou clorofila clorobium (bactérias sulfurosas verdes). Outros autores, como Wetzel (1983) indicam a existência da Clorofila_d em certos organismos aquáticos, mas em concentrações muito baixas e sem função claramente definida. Duas outras classes de pigmentos que estão envolvidas na captura de energia luminosa são os carotenóides e as ficobilinas. Segundo Raven et al (2001), a energia absorvida por estes pigmentos acessórios precisa ser transferida para a Clorofila_a, da mesma forma que a Clorofila_b e Clorofila_c.

Portanto, a Clorofila_a é o pigmento mais importante na verificação da presença global de organismos fotossintetizantes na água. Os outros tipos de clorofilas e demais pigmentos são úteis como forma de identificar a presença ou dominância de certa classe de alga em uma amostra, como é discutido em Ansotegui et al (2001).

Para determinação de pigmentos do fitoplancton, três métodos podem ser utilizados: espectrofotometria, fluorometria e cromatografia líquida de alta resolução (HPLC). Para clorofilas, o método laboratorial mais empregado é o espectrofotométrico, que se baseia na absorção de luz em comprimentos de onda definidos. Este método tem a desvantagem de requerer volumes relativamente grandes de amostras de água, principalmente em situaçôes de baixa concentração de pigmentos. Neste caso, a fluorometria desponta como método mais prático quando se deseja avaliar um número grande de pontos amostrais e para determinações in vivo. Pinto et al (2001) apresentam e discutem aplicações do método fluorométrico para determinação da Clorofila_a. Por sua vez, o HPLC é útil para quantificar uma vasta gama de pigmentos fotossintéticos, incluídos Clorofila_a, pigmentos acessórios (como clorofilas b e c) e produtos de degradação de clorofilas. Este método é utilizado em estudos da composição do fitoplancton em certos ambientes aquáticos.

\section{MATERIAIS E MÉTODOS}

Os procedimentos, materiais e dispositivos utilizados no trabalho podem ser enquadrados em três grupos: (1) caracterização hidro-geográfica da Lagoa da Conceição, (2) coleta e análise de amostras de água da superfície da lagoa e (3) seleção, aquisição e interpretação de imagem de satélite.

No grupo 1 de procedimentos, a caracterização da lagoa foi realizada com base em cartas geográficas do IBGE em escala 1:50.000, em levantamento batimétrico efetuado por Muehe \& Gomes Jr. (1989) e em modelo digital da batimetria da lagoa produzido no Sistema de Informaçôes Geográficas Idrisi (2003).

No grupo 2, foram coletadas amostras de água da superfície da Lagoa da Conceição em cinco pontos distribuídos na Lagoa de Baixo e Lagoa do Meio (Figura 1). As datas das amostragens prováveis foram selecionadas com base nas datas de passagens dos satélites disponíveis ao longo do estudo (inicialmente Landsat ETM 7 e CBERS1, posteriormente Landsat TM 5). Entretanto, poucas datas dentro do cronograma de passagem dos satélites puderam ser utilizadas, já que as condiçôes meteorológicas, na maioria das vezes, não se apresentavam adequadas. Mesmo assim, ao longo do período de estudo foram feitas sete campanhas de coleta de água nos pontos amostrais e em quatro delas foi possível realizar análises para teores de pigmentos. Por sua vez, os parâmetros analisados nas amostras foram clorofilas, Seston, pH e temperatura. Os parâmetros foram escolhidos principalmente em função de seus efeitos à cor das águas e emissão de calor, já que essas características superficiais de espelhos líquidos podem ser correlacionadas com os dados registrados pelos sensores orbitais embarcados nos satélites.

A determinação dos diferentes tipos de clorofila foi realizada por es- pectrofotometria, com procedimentos analíticos realizados de acordo com metodologia descrita em USEPA (1994), com substituição da acetona pelo dimetilsulfóxido como extrator. $\mathrm{O}$ Seston foi obtido por secagem em estufa e pesagem de precisão do resíduo retido em filtro de papel. Os parâmetros $\mathrm{pH}$ e temperatura foram medidos in loco com sonda portátil.

Como já foi apontado, não houve possibilidade de aquisição de imagens orbitais coincidentes com as coletas de amostras de água. Dessa forma, o grupo 3 de procedimentos compreendeu a aquisição de imagem Landsat TM5 com passagem em 12/08/2003, sete dias antes de uma das campanhas de coleta de amostras (20/08/2004). De posse da imagem Landsat TM5 do local de estudo, realizou o seu processamento com técnicas padrôes descritas em Eastman (1997), Malingreau (1989) e Mendes et al (1991). A correlação das informações adquiridas por satélite e das coletas in situ permitiu a espacialização da distribuição do teor de clorofila ao longo de toda a Lagoa da Conceição, tarefa realizada em Sistema de Informações Geográficas (Idrisi, 2003).

\section{RESULTADOS E DISCUSSÂO}

As principais variáveis analisadas nas águas superficiais da Lagoa da Conceição ao longo do projeto foram os pigmentos Clorofila $a$ e $b$ (a Clorofila_c não foi detectada) e matéria particulada ou Seston. As concentrações de Clorofila_a, Clorofila_b e Seston medidas em cinco pontos da Lagoa da Conceição em 20 de agosto de 2003 são apresentadas na Tabela 1.

Com relação ao Seston, pode-se verificar que os valores encontrados foram pequenos em todos os cinco pontos amostrados, indicando baixa presença de material em suspensão na camada superficial de água. Em três pontos o nível encontrado foi inferior a $1 \mathrm{~g} / \mathrm{m}^{3}(<1,0 \mathrm{mg} / \mathrm{l})$ e nos pontos $2 \mathrm{e}$ 3 obteve-se níveis de 2,6 e 2,3 g/ $/ \mathrm{m}^{3}$, respectivamente. Estes últimos valores, ainda assim muito baixos, possivelmente resultaram do revolvimento do fundo da lagoa em função do vento nordeste que soprava no momento da coleta. Destaquese que níveis baixos de Seston também foram obtidos por Odebrecht e Gomes Jr (1999), principalmente na porção da lagoa denominada Lagoa do Meio. 
Dessa forma, pode-se considerar que as águas da lagoa possuem boa transparência e isso pode favorecer o desenvolvimento de organismos bentônicos autotróficos, principalmente em locais em que água possui baixa circulação horizontal. Esse é caso do ponto 1, localizado na porção "Lagoa de Baixo", no qual pôde-se observar ao longo da duração do projeto um grande desenvolvimento de macroalgas bentônicas e flutuantes. No tocante ao registro dos níveis radiométricos dessas áreas por parte de sensores orbitais, deve-se esperar como resposta uma reflectância maior do que o esperado para certos comprimentos de onda, uma vez que a alta transparência da água permite que seja registrada a reflexão dos materiais que compóem o fundo da lagoa. Essa reflexão tenderá a ser tanto maior quanto menor for a profundidade, condição que limita a detecção de cor da água apenas naquelas porções mais profundas da lagoa.

Quanto às concentrações de Clorofila_a e Clorofila_b listadas na Tabela 1, inicialmente deve-se apontar o fato de que os níveis de Clorofila_b são mais altos do que os de Clorofila_a em quatro dos cinco pontos amostrados, quando se esperavam resultados justamente opostos, pois em amostragem anterior (resultados aqui não listados) foram obtidas razôes
Clorofila_a/Clorofila_b entre 2,5 e 3,5. Em um primeiro momento chegou-se a pensar em erros nas medições, mas a repetição das análises uma semana após revelou tendência similar (embora as diferenças nas concentraçóes dos dois pigmentos tenham sido menores). Como se entendeu que tal "anomalia" não implicava interferências no trabalho, não foram procuradas suas causas, que podem residir nas variações das populações de certas tipos ou espécies de organismos fotossintetizantes, em diferenças nas taxas de degradação dos dois pigmentos ao longo da coluna de água ou em outras causas não determinadas.

Pelos dados da Tabela 1, pode-se observar que os pontos 4 e 5 apresentaram níveis mais baixos de pigmentos do que os outros três, fato que pode ser mais bem evidenciado quando se comparam as somas de Clorofila_a e Clorofila_b. Nesses pontos, que se situam na porção lagunar denominada Lagoa do Meio, o intercâmbio com águas menos ricas oriundas do oceano é mais acentuado devido ao maior contato com eventuais correntes de refluxo provenientes do canal da Barra da Lagoa. Nos pontos 1, 2 e 3, por outro lado, as águas possuem maior tempo de residência, fator favorável ao desenvolvimento de organismos fotossintetizantes devido principalmente à maior disponibilidade de nutrientes. Destaque-se, no entanto, que a Lagoa possui uma dinâmica complexa que envolve mecanismos de re-circulação de água entre suas três grandes porções, fato que pode alterar periodicamente as condições nutricionais em cada uma delas.

Para atender a principal meta do estudo - obter uma estimativa da distribuição espacial da Clorofila_a ao longo da Lagoa da Conceição - foram correlacionados os dados medidos na campanha realizada em 20/08/2003 com dados de reflectância adquiridos por sensores embarcados no satélite Landsat TM5 em 12/08/2003. Inicialmente, as diversas bandas da cena Landsat TM5 adquirida foram trabalhadas no Sistema de Informações Geográficas Idrisi para registro ("georreferenciamento"), correção atmosférica do sinal captado pelos sensores e transformação dos níveis de cinza em níveis de reflectância relativa. Os dados de Clorofila_a medidos nos cinco pontos amostrais e respectivos níveis de reflectância relativa em quatro bandas (bandas 1, 2, 3 e 4), além de Temperaturas Superficiais da Água (TSA) obtidas pela banda 6, estão listados na Tabela 2.

Para interpretar os valores de reflectância registrados pelos sensores orbitais foram testadas diversas combinaçōes de bandas, principalmente a modalidade razão entre bandas. Porém,

Tabela I - Concentrações de Clorofila_a (Cl_a), Clorofila_b (Cl_b) e Seston medidas em amostras coletadas no dia 20/08/2003 em cinco pontos da superfície da Lāoa da Conceição, Florianópolis (SC)

\begin{tabular}{ccccccc}
\hline Ponto & Localidade & Coordenadas & \multicolumn{4}{c}{ Parâmetros } \\
& & UTM & $\begin{array}{c}\text { Seston } \\
\left(\mathrm{g} / \mathrm{m}^{3}\right)\end{array}$ & $\begin{array}{c}\mathrm{Cl} \text { a } \\
\left(\mathrm{mg} / \mathrm{m}^{3}\right)\end{array}$ & $\begin{array}{c}\text { Cl_b } \\
\left(\mathrm{mg} / \mathrm{m}^{3}\right)\end{array}$ & $\begin{array}{c}\text { Cl_a }+\mathrm{Cl}\left(\mathrm{mg} / \mathrm{m}^{3}\right) \\
(1, b\end{array}$ \\
\hline 1 & Canto da Lagoa & $748680 / 6943812$ & $<1,0$ & 3,1 & 8,5 & 11,6 \\
2 & Lagoa baixa & $750159 / 6943715$ & 2,6 & 4,5 & 10,4 & 14,9 \\
3 & Início Rendeiras & $752479 / 6943577$ & 2,3 & 7,6 & 9,0 & 16,6 \\
4 & Rest. Caranhas & $753003 / 6945436$ & $<1,0$ & 2,8 & 3,4 & 6,2 \\
5 & Canto Araçás & $750691 / 6946137$ & $<1,0$ & 2,5 & 1,5 & 4,0 \\
\hline
\end{tabular}

Tabela 2 - Concentração medida de Clorofila_a (Cl_a), reflectâncias relativas (em decimais) obtidas em quatro bandas do satélite Landsat TM5 e Temperatura Superficial da Água (TSA) registrada pela banda 6 em cinco pontos da Lagoa da Conceição (Florianópolis, SC)

\begin{tabular}{cccccccc}
\hline Ponto & Local & $\begin{array}{c}\mathrm{Cl} \_\mathrm{a} \\
\left(\mathrm{mg} / \mathrm{m}^{3}\right)\end{array}$ & $\rho_{\mathrm{TM} 1}$ & $\rho_{\mathrm{TM} 2}$ & $\rho_{\mathrm{TM} 3}$ & $\rho_{\mathrm{TM} 4}$ & TSA ( $\left.{ }^{\circ} \mathrm{C}\right)$ \\
\hline 1 & Canto da Lagoa & 3,1 & 0,104 & 0,0317 & 0,0412 & 0,00038 & 15,9 \\
2 & Lagoa Baixa & 4,5 & 0,105 & 0,0304 & 0,0447 & 0,00043 & 16,4 \\
3 & Início Rendeiras & 7,6 & 0,105 & 0,0221 & 0,0372 & 0,00046 & 15,7 \\
4 & Rest. Caranhas & 2,8 & 0,116 & 0,0526 & 0,0587 & 0,00039 & 15,7 \\
5 & Canto dos Araçás & 2,5 & 0,105 & 0,0329 & 0,0434 & 0,00052 & 16,1 \\
\hline
\end{tabular}


nenhuma das combinações testadas revelou mais informação do que qualquer banda isoladamente, motivo pelo qual não serão apresentadas aqui.

Para determinar as relações entre energia eletromagnética nas bandas reflexivas do Landsat TM5 e os parâmetros Clorofila_a, Clorofila_b e Clorofila Total foram adotadas técnicas estatísticas, principalmente a modalidade regressão múltipla. Diversos modelos foram testados, mas obteve-se melhor resultado pela relação entre valores de reflectância corrigidos nas bandas TM1 e TM2 ( $\rho_{\text {TM1 }}$ e $\rho_{\mathrm{TM} 2}$, respectivamente) e concentraçōes de Clorofila_a, dada por:

$$
\mathrm{Cl}_{-} \mathrm{a}\left(\mathrm{mg} / \mathrm{m}^{3}\right)=735,98 \rho_{\mathrm{TM} 1}-425,88 \rho_{\mathrm{TM} 2}-
$$$$
-60,20 \quad \mathrm{R}^{2}=0,96
$$

A Figura 2 mostra graficamente a relação entre os valores medidos in situ e estimados pelo modelo estatístico derivado das bandas 1 e 2 do Landsat TM5.

Finalmente, com a aplicação do modelo na área da Lagoa da Conceição obteve-se a distribuição espacial da Clorofila_a exibida na Figura 3. Na Tabela 4, por sua vez, apresentam-se as áreas ocupadas por cada classe de concentração de clorofila listadas na Figura 3.

A distribuição de Clorofila_a ao longo da Lagoa da Conceiçãoo (Figura 3) foi obtida pela aplicação de modelo de regressão múltipla calculado a partir dos dados medidos in situ e valores de reflectância registrados nas bandas 1 e 2 do Landsat TM5, que constam na Tabela 2. A escolha das bandas 1 e 2 para entrada no modelo de estimativa foi puramente estatística, isto é, baseou-se apenas no melhor ajuste dessas bandas com os dados medidos. Deve-se reparar que em parte expressiva da lagoa optou-se por não realizar a distribuição de clorofila pelo modelo, uma vez que nela há fortes interferências de reflexão do fundo devido às pequenas profundidades da lâmina de água. Embora fossem tentadas várias alternativas de tratamento de imagens para minimizar os efeitos do fundo, tais como aplicação de diversos tipos de filtros e combinaçôes aritméticas de bandas, os resultados foram pífios. Dessa forma, a distribuição de Clorofila_a foi estimada apenas para as partes mais profundas $\mathrm{da}$ Lagoa (em geral com mais de $1 \mathrm{~m}$ de profundidade).

Comparando-se os valores medidos/estimados com os apontados na literatura como indicativo do estado trófico das águas (por exemplo, em Boyd, 2000), pode-se verificar que as águas da Lagoa da Conceição podem ser classificadas entre oligotróficas e mesotróficas. No primeiro grupo pode-se enquadrar as classes da Figura 3 denominadas " $<2,5 \mathrm{mg} / \mathrm{m}^{3}$ " $\mathrm{e}$ “2,5-5,0 mg/m 3 ", que ocupam em conjunto aproximadamente $45 \%$ da superfície da lagoa (note-se que cerca de $48 \%$ da lagoa ficou de fora da distribuição devido ao problema de interferência do fundo). Como mesotróficas pode-se considerar as porções da lagoa enquadradas nas classes “5,0-7,5 mg/m" e " $>7,5 \mathrm{mg} / \mathrm{m}^{3}$ ", que ocupam apenas cerca de $8 \%$ da superfície total da lagoa.

A partir da espacialização dos dados de Clorofila_a exibidos na Figura 3, pode-se observar que a maior parte da Lagoa da Conceição tende apresentar baixa produtividade primária, o que determina estética agradável às águas devido aos níveis baixos de fitoplâncton. No entanto, também pode apresentar porçôes que, apesar de pouco significativas na área ocupada, tem redução no apelo estético ocasionada pela presença de alguma turbidez algal. Deve-se considerar como improvável a depleção de oxigênio nessas porçôes, situação que ocorre em níveis de clorofila na água mais altos. A questão a ser considerada por futuros monitoramentos é quanto à expansão das áreas nas classes com maiores níveis de clorofila, situação que poderá revelar um processo de eutrofização cultural nesse corpo hídrico.

Das limitações percebidas na aplicação de monitoramento orbital às águas da Lagoa da Conceição, a mais forte está relacionada à grande superfície desse corpo hídrico ocupada por águas rasas, nas quais a cor da água é mascarada pela cor do sedimento de fundo. Nesses locais, em compensação, existem aplicações promissoras quanto à identificação de áreas ocupadas por algas bentônicas, que podem ser utilizadas como parâmetro indicativo do estado trófico das águas. Essa possibilidade deverá ser investigada no futuro. Finalmente, quanto aos métodos analíticos utilizados no estudo para avaliação do teor de pigmentos na água, deve-se apontar que eles são pouco adequados

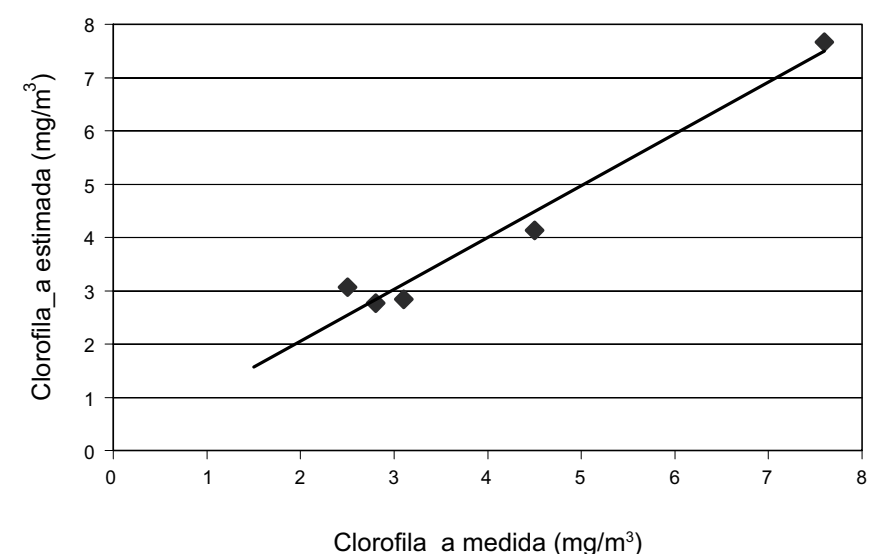

Figura 2 - Concentrações de Clorofila_a calculadas utilizando equação de regressão obtida por dados Landsat TM5 plotados versus concentrações de Clorofila_a medidas in situ (Lagoa da Conceição, Florianópolis, SC)

Tabela 3 - Distribuição espacial das classes de concentração de Clorofila a na Lagoa da Conceição (Florianópolis, SC)

\begin{tabular}{ccc}
\hline $\begin{array}{c}\text { Classes de concentração } \\
\left(\mathrm{mg} / \mathrm{m}^{3}\right)\end{array}$ & $\begin{array}{c}\text { Área } \\
(\mathrm{ha})\end{array}$ & $\begin{array}{c}\text { Percentual } \\
(\%)\end{array}$ \\
\hline Não determinado $^{1}$ & 920 & 47,8 \\
$<2,5$ & 399 & 20,7 \\
$2,5-5,0$ & 457 & 23,8 \\
$5,0-7,5$ & 113 & 5,9 \\
$>7,5$ & 35 & 1,8 \\
Total & 1924 & 100,0
\end{tabular}

${ }^{\mathrm{I}}$ Regiōes lagunares rasas 


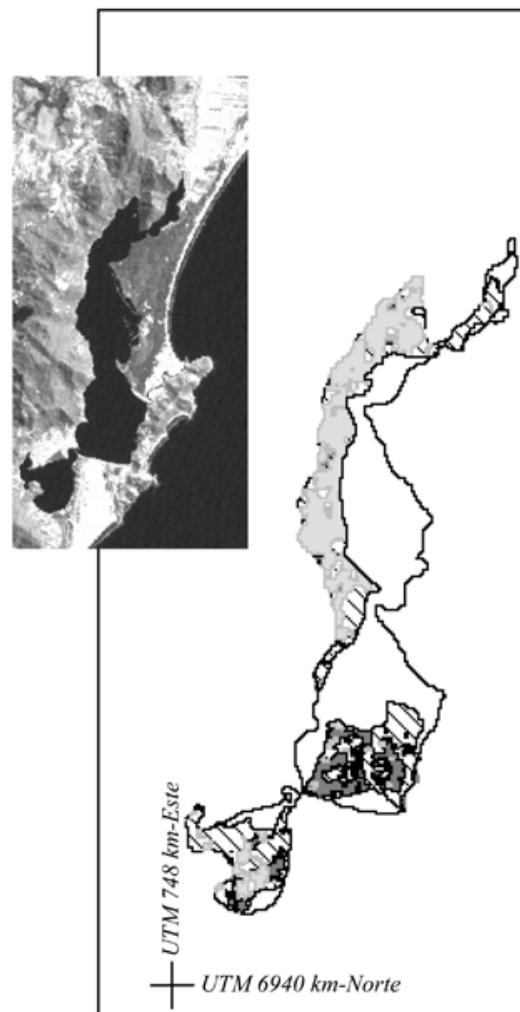

JOINT, I.; GROOM, S. B. Estimation of phytoplancton production from space: current status and future potential of satellite remote sensing. Journal of experimental marine Biology and Ecology. Vol. 250:233-255, 2000.

KESTER, D. R.; FOX, M. F.; MAGNUSON, A. Modeling, measurements, and satellite remote sensing of biologically active constituints in coastal waters. Marine Chemistry 53. 131-145. 1996.

MALINGREAU, J.P. The vegetation index and the study of vegetation dynamics. In: Toselli (Ed.). Applications of Remote Sensing to Agrometeorology. ECSC-EEC-EAEC: 285-303, 1989.

MENDES, A. et al. Avaliação de parâmetros de qualidade da água através de técnicas de sensoriamento remoto. RBE 9(2):9-23, 1991.

MUEHE, D.; GOMES JR., F. C. Batimetria e algumas consideraçôes sobre a evolução geológica da Lagoa da Conceição, Ilha de Santa Catarina. In: LEDO, B. S. de; SORIANO-SERRA, E.J. (Eds.) O ecossistema da Lagoa da Conceição. Florianópolis: NEMAR/CCB/UFSC: SDM/FEPEMA, Cap. 2:15-24, 1999

ODEBRECHT, C.; GOMES JR., F.C. Hidrografia e matéria particulada em suspensão na Lagoa da Conceição, Ilha de Santa Catarina, SC, Brasil. In LEDO, B. S. de; SORIANO-SERRA, E.J. (Eds.). O ecossistema da Lagoa da Conceição. Florianópolis: NEMAR/CCB/UFSC: SDM/FEPEMA, Cap. 3:35-61, 1999.

Figura 3 - Distribuição de Clorofila_a na Lagoa da Conceição (Florianópolis, SC) gerada a partir de equação de regressão obtida por dados Landsat TM5 plotados versus concentrações de Clorofila_a medidas in situ

para condiçôes de baixa concentração como as verificadas em algumas porções da Lagoa da Conceição, uma vez que exigem amostras com volumes relativamente altos para detecçóes sensíveis. A necessidade de volumes altos limita o número de amostras que podem ser analisadas, pois $\mathrm{o}$ processo de filtragem e extração demanda tempo apreciável para ser realizado. Para o tipo de estudo proposto, estima-se que o ideal seja empregar fluorômetro para detecção de pigmentos na água, como recomendam Pinto et al (2001), porém os autores deste trabalho não dispuseram de uma unidade desse equipamento para testes e avaliaçóes ao longo do período de duração do projeto.

\section{AGRADECIMENTOS}

Os autores registram seus agradecimentos aos Professores Marcelo Maraschin (Fitotecnia/UFSC), Jarbas Bonetti (Aqüicultura/UFSC) e Mônica A. A. dos Santos (Enga Rural/UFSC) pelas contribuiçôes prestadas ao longo do projeto. Agradecem também aos revisores anônimos pelas suas sugestôes e correçóes, as quais melhoram o texto final do trabalho.

\section{REFERÊNCIAS}

ANSOTEGUI, A.; TRIGUEROS, J.M.; ORIVE, E. The use of pigments signatures to assess phytoplankton assemblage structure in estuarine waters. Estuarine, Coastal and Shelf Science, 52:689-703, 2001.

BOYD, C.E. Water quality: an introduction. Norwell, Massachusetts: Kluwer Academic Publishers, 2000.

EASTMAN, J. R. Idrisi for Windows $v 2$ - User's Guide. Clarks Labs, 1997.

EKSTRAND, S. Determination of algal production in na industrial waste water plume using Landsat TM satellite imagery. Estocolmo: Report of Swedish Environmental Research Institute, 1998.

ESTEVES, F. A. \& BARBOSA, F. A.R. Eutrofização artificial: a doença dos lagos. Ciência Hoje (SBPC), vol. especial, maio de 1992.

ESTEVES, F. A. Fundamentos de limnologia. Rio de Janeiro: Interciência: Finep, 1988.

GIARDINO, C. et al. Detecting chlorophyll, Secchi disk depth and surface temperature in a sub-alpine lake using Landsat imagery. The Science of the Total Environment, Vol. 268:19-20, 2001.

IDRISI. Versão 14.01-Kilimanjaro. IDRISI Project. Universitys George Perkins Marsh Institute at Clark University in Worcester, Massachusetts, USA, 2003.

JOHANNESSEN, O. M. et al. Satellite earth observation in operational oceanography. Coastal Enginnering, Vol. 41:155-176, 2000.
PATIL, A. A.; ANNACHHATRE, A.P.; TRIPATHI, N.K. Comparison of conventional and geo-spatial EIA A shrimp farming case study. Environmental Impact Assessment Review, Vol. 22:353-366, 2002.

PEREZ Fo, A.; QUINTONES, E.M. Uso da técnica de sensoriamento remoto na avaliação da qualidade da água em represas. Eng. Agríc., Jaboticabal, v.16, n.3, p.62-68, mar. 1997.

PINTO, A.M.F.; VON SPERLING, E.; MOREIRA, R.M. Chlorophyll_a determination via continuous measurement of plankton fluorescence: methodology development. Wat. Res., Vol. 35(16):3977-3981, 2001.

RAVEN, P.H.; EVERT, R.F.; EICHORN, S.E. Biologia Vegetal. 6a. edição. Rio de Janeiro: Guanabara Koogan, 2001.

USEPA. Chlorophyll determination. SOP\#:2030, 11/17/94. Disponível em: <htpp://www. ertresponse.com/sops/2030.pdf >. Acesso em: 28 outubro de 2003.

WETZEL, R. G. Limnology. 2a. edição. Saunders College Publishing, 1983.

Endereço para correspondência:

Luiz C. P. Martini

Centro de Ciências Agrárias

Universidade Federal de Santa

Catarina

Rod. Admar Gonzaga, I 346

88034-00I - Florianópolis - SC

- Brasil

Email: Imartini@cca.ufsc.br 